\title{
Physicochemical Properties and Storage Stability of Food Protein-Stabilized Nanoemulsions
}

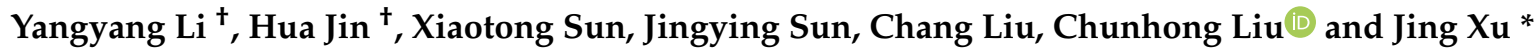 \\ College of Science, Northeast Agricultural University, Harbin 150030, Heilongjiang, China; \\ ccwasdrdxnlyy@126.com (Y.L.); jinhua@neau.edu.cn (H.J.); sunxt0523@163.com (X.S.); \\ asunjinying@126.com (J.S.); aaxuchang@126.com (C.L.); liuchunhong@neau.edu.cn (C.L.) \\ * Correspondence: xujing@neau.edu.cn; Tel.: +86-13796652155 \\ † These authors contributed equally to this work.
}

Received: 29 November 2018; Accepted: 18 December 2018; Published: 25 December 2018

check for updates

\begin{abstract}
This study investigated the preparation and properties of corn oil nanoemulsions stabilized by peanut protein isolate (PPI), rice bran protein isolate (RBPI), soybean protein isolate (SPI), and whey protein isolate (WPI). The mean droplet diameter of four protein-stabilized nanoemulsions prepared via ultrasound method was less than $245 \mathrm{~nm}$. PPI-stabilized nanoemulsions showed better stability for 4 weeks, while the mean droplet diameter of RBPI-stabilized nanoemulsions had exceeded $1000 \mathrm{~nm}$ during the third week of storage. Fourier transform infrared and interfacial tension (IT) analysis showed that the higher level of disordered structure and lower IT of proteins made the stability of nanoemulsions better. Moreover, bivariate correlation analysis discovered that $\alpha$-helix $(p<0.01)$ and $\beta$-turn $(p<0.05)$ of proteins were related to the mean droplet diameter of nanoemulsions, the random coil $(p<0.05)$ was related to the zeta potential of nanoemulsions. This study provided new idea for the relationship between the structure of protein and properties of protein-stabilized nanoemulsions.
\end{abstract}

Keywords: ultrasound; proteins; nanoemulsions; physicochemical properties; storage stability

\section{Introduction}

Nanoemulsions are composed by minute oil droplets (average droplet diameter less than $500 \mathrm{~nm}$ ) which are maintained in the aqueous phase. Each nanoemulsion oil droplet is usually stabilized by emulsifier molecules. Unlike most traditional emulsions, nanoemulsions can resist gravitational settling or coalescence more effectively, and they are overall more stable as they possess larger surface area of droplets [1]. Moreover, nanoemulsions can be designed to have different rheological, optical, and stability features via control of their structures and compositions [2-4]. Therefore, nanoemulsions have acted as an excellent system for the encapsulation and delivery of bioactive compounds which are lipophilic in nature.

The nanoemulsions characteristics, such as the droplet size distribution, optical and rheological stability, are governed by emulsification technologies and emulsifier types [5]. High and low energy emulsification approaches are usually employed for nanoemulsions preparation. Spontaneous emulsification (microemulsion dilution and solvent diffusion) and phase transition (by adjusting component or temperature) are two commonly used low energy emulsification approaches [6]. High energy emulsification approaches include high pressure homogenization, microfluidization and ultrasound, which can generate strong destructive forces and disrupt large droplets into smaller ones, thereby mixing the oil phase and the water phase. Compared with low energy emulsification methods, high energy approaches are more frequently utilized to produce nanoemulsions, especially in large scale production of food industry. The ultrasonic cavitation can increase diffusion rates and 
disperse aggregates in the formation of nanoemulsions [7-9]. As determined in previous studies, when producing nanoemulsions with a given droplet size, the efficiency of ultrasound-based approach is 18 times higher than that of microfluidization [10]. Additionally, ultrasonic techniques are lower cost, requiring less maintenance and handling time than other mechanical approaches. At present, ultrasonic approaches are widely used for nanoemulsions preparation [11-15].

At the beginning, several synthetic surfactants (including Tweens and Spans) were used as high performance emulsifiers to prepare nanoemulsions. However, considering that the safety of emulsifiers is of crucial importance in food products, the potential toxicity of synthetic surfactants limits their applications in food industry $[16,17]$. So now there has been a growing attention to the use of food-grade emulsifiers. In recent years, studies have uncovered that food proteins have great potential as safe stabilizers for nanoemulsions [18]. The earliest food proteins as stabilizers for nanoemulsions are animal proteins, such as milk and egg proteins. Subsequently, vegetable proteins, such as those from soy beans and peas, have also become prevailing, because of their good emulsifying ability [19-22].

Peanut protein and rice bran protein have not only high nutritional value, but also their functional characteristics which have attracted people's attention [23]. Zhang and $\mathrm{Lu}$ (2015) found that peanut protein adsorbed on the oil/water interface in emulsions possessed higher emulsification [24]. Zhang et al. (2017) have demonstrated that ultrasound treatment could unfold the conformation of rice bran protein, exposing its interior functional groups, which were related to its emulsifying property [25]. However, the efficacies of ultrasound-mediated preparation of nanoemulsions from peanut protein and rice bran protein remain largely unknown.

The objectives of our work were to evaluate the properties of ultrasound-mediated corn oil nanoemulsions with peanut protein isolate (PPI) and rice bran protein isolate (RBPI) as stabilizers. During the research, soybean protein isolate (SPI, vegetable proteins) and whey protein isolate (WPI, animal proteins) were used as reference. The secondary structure and interfacial tension of PPI, RBPI, SPI, and WPI were evaluated. And the relationship between the secondary structure of proteins and the forming ability of proteins-stabilized nanoemulsions was analyzed by bivariate correlation analysis. The study provided new information for enhancing the comprehension of peanut protein isolate and rice bran protein isolate as emulsifiers to fabricate food-grade nanoemulsions. Simultaneously, the research provided elementary idea for the mechanism of protein emulsifiers stabilizing nanoemulsions.

\section{Materials and Methods}

\subsection{Materials}

Protein isolate of peanut, rice bran, soybean, and whey were supplied from Harbin High-Tech Co. (Harbin, China). Corn oil was obtained from a local grocery. Nile red and Nile blue were from Sigma-Aldrich (St. Louis, MO, USA). Butylated hydroxytoluene (BHT) was purchased from Merck Co. (Darmstadt, Germany). Trichloroacetic acid (TCA) was from Samchun Pure Chemicals Co. Ltd. (Seoul, Korea). Analytical-grade reagents were used unless otherwise stated.

\subsection{Nanoemulsions Preparation}

Corn oil (1-20\% $v / v$, respectively) and aqueous phase (10 $\mathrm{mM}$ phosphate buffer, $\mathrm{pH} 7.0)$ containing peanut protein isolate (PPI) $(1-8 \% w / v)$, rice bran protein isolate (RBPI) $(1-4 \% w / v)$, SPI $(1-7 \% w / v)$, or WPI $(1-10 \% w / v)$ were coarsely mixed by a benchtop stirrer. To prevent microbial growth, sodium azide $(0.004 \%, w / v)$ was added. The mixtures of corn oil and protein dispersions were further blended via homogeniser (FJ200-SH, Shanghai specimen model factory, Shanghai, China) at 10,000 rpm for 4 minutes to obtain coarse emulsions. Then, an ultrasonic processor (Ningbo Xinzhi Biotechnology Co. Ltd., Ningbo, China) with a $0.636 \mathrm{~cm}$ diameter titanium probe immediately processed $20 \mathrm{~mL}$ of the coarse emulsions at a determined ultrasonic power $(100-500 \mathrm{~W}$, corresponding to the amplitude of $10-50 \%$ ) and time (5-25 $\mathrm{min}$, pulse duration of on-time $2 \mathrm{~s}$ and off-time $3 \mathrm{~s}$ ). 
In the process of nanoemulsions preparation, the temperature was controlled at $25^{\circ} \mathrm{C}$ by means of ice-water bath.

\subsection{Droplet Size, Zeta Potential and Apparent Viscosity Measurements}

The mean droplet diameter (MDD) of nanoemulsions was determined using a dynamic light scattering (Zetasizer Nano-ZS90, Malvern Instruments, Worcestershire, UK). The particle size results were reported as the Z-average mean diameter calculated from the particle size distribution. To avoid multiple light scattering effects, nanoemulsions were diluted 100-fold with $10 \mathrm{mM}$ phosphate buffer ( $\mathrm{pH}$ 7.0) and agitated well at $25^{\circ} \mathrm{C}$. The refractive index values used for oil (corn oil) and dispersant (phosphate buffer) were 1.47 and 1.33 , respectively.

The zeta potential (ZP) of nanoemulsions systems was investigated using an electrophoresis (Zetasizer Nano-ZS90, Malvern Instruments, Worcestershire, UK). The nanoemulsions were diluted 100 -fold with $10 \mathrm{mM}$ phosphate buffer ( $\mathrm{pH}$ 7.0) and agitated well at $25^{\circ} \mathrm{C}$ prior to measurement so as to avoid multiple scattering effects.

The apparent viscosity of nanoemulsions was measured based on shear rate $\left(0.01-100 \mathrm{~s}^{-1}\right)$ via a rheometer (DHR-1, TA Instruments, New Castle, PA, USA) in rotational mode. A 40 mm acrylic parallel plate with a $500 \mu \mathrm{m}$ geometric gap was slowly placed on the sample and equilibrated for $30 \mathrm{~s}$, and then shear was applied for measurement at $25^{\circ} \mathrm{C}$.

\subsection{Confocal Laser Scanning Microscopy}

The dyed nanoemulsions were prepared using Nile red dye $(0.1 \mathrm{mg} / \mathrm{mL}$ isopropanol $)$ in the oil phase and Nile blue dye ( $1 \mathrm{mg} / \mathrm{mL}$ isopropanol) in the aqueous phase. The dyed nanoemulsions were inspected on a slide with a cover slip using the $63 \times$ oil immersion objective lens of a confocal laser scanning microscope (CLSM) (Nikon C2, Nikon lnc., Mississauga, ON, Canada). The dyes were excited using 488 and $633 \mathrm{~nm}$ lasers.

\subsection{Storage Stability}

For testing storage stability, the PPI, RBPI, SPI, and WPI-stabilized nanoemulsions were fabricated under the circumstance of the different protein concentrations of PPI $(2 \% w / v)$, RBPI $(2 \% w / v)$, SPI $(3 \% w / v)$ and WPI $(4 \% w / v)$, corn oil $(3 \%, 2 \%, 2 \%, 3 \% v / v$, respectively), ultrasonic power $500 \mathrm{~W}$ and time $20 \mathrm{~min}$. The influence of reserve time on nanoemulsions was evaluated under the condition of $4{ }^{\circ} \mathrm{C}$ for 4 weeks.

\subsubsection{Physical Stability Measurement}

The physical stability of nanoemulsions was assessed by determining particle size changes per 7 days of storage.

\subsubsection{Oxidative Stability Measurement}

To assess secondary oxidation products, thiobarbituric acid-reactive substances (TBARS) were measured as previously described by [26]. TBARS levels were established according to 1,1,3,3-tetraethoxypropane standard curve.

\subsection{Fourier Transform Infrared (FTIR) Spectroscopy of Protein}

Infrared spectra of the four different protein samples (PPI, RBPI, SPI, and WPI) were obtained with Bruker Vertex 70 FTIR spectrometer (Bruker Optics, Ettlingen, Germany) via wavenumber ranging from 4000 to $400 \mathrm{~cm}^{-1}$. All datas were collected with $4 \mathrm{~cm}^{-1}$ window and were the average results of 64 scans. Analyze the secondary structure of four different protein using the software "Peakfit Version 4.12" and the "Gaussian peak fitting" algorithm [27]. 


\subsection{Interfacial Tension (IT) Measurement of Protein}

The interfacial tension at different concentrations of PPI, RBPI, SPI, and WPI was determined against corn oil using a Du Nouy ring tensiometer (TP681, Timepower, Co., Ltd., Beijing, China) at $25{ }^{\circ} \mathrm{C}$.

\subsection{Statistical Analysis}

All experiments were conducted in triplicate. Results were expressed as mean \pm standard deviation. Significance of difference between the means was identified through the Duncan's multiple-range tests $(p<0.05)$ with SPSS 20.0 software (New York, NY, USA). Pearson's correlation analysis was conducted to determine the coefficients reflecting the relationship between the secondary structure of proteins and the forming ability of proteins-stabilized nanoemulsions.

\section{Results and Discussion}

\subsection{Effects of Protein Concentrations on Nanoemulsions MDD and ZP}

Effects of different protein concentrations of PPI (1-8\% w/v), RBPI (1-4\% $w / v)$, SPI $(1-7 \% w / v)$, and WPI $(1-10 \% w / v)$ on nanoeumlsions MDD were measured (Figure $1 \mathrm{a})$. When the concentration of the emulsifier was low (PPI $<2 \% w / v$, RBPI $<2 \% w / v$, SPI $<3 \% w / v$ and WPI $<4 \% w / v$ ), the mean droplet diameter decreased significantly $(p<0.05)$ as the concentration increased, because more emulsifier molecules were available to cover more oil-water interfacial areas during the preparation of nanoemulsions. When the emulsifier concentration became higher, the mean droplet diameter remained properly constant, as there were enough emulsifiers covering all the newly formed oil droplets surfaces, thereby the particle size of nanoemulsions no longer continued to decrease [28,29]. Moreover, from Figure 1a, it should be noticed that there was followed by another increase trend of MDD when the concentration of protein further increased to a certain degree. This phenomenon was attributed to the fact that the numbers of interfacial sites were insufficient for the large number of protein molecules and unabsorbed protein molecules led to the aggregation in aqueous phase [30]. The protein concentration required to produce droplets with smallest MDD was $2 \%$ for PPI, 2\% for RBPI, 3\% for SPI, and 4\% for WPI, the corresponding MDD was 251.13 $\pm 5.35,294.60 \pm 7.83$, $256.27 \pm 8.41$ and $266.50 \pm 10.57 \mathrm{~nm}$ respectively. The results indicated that PPI and RBPI were more efficient at debasing particle size of nanoemulsions $(\mathrm{pH} 7.0)$ when they were at lower protein concentrations $(2 \% w / v)$.

Zeta potential $(\mathrm{ZP})$ is another important indicator of nanoemulsions stability. Because the surface charge highly commands the interactions between droplets in nanoemulsions. All nanoemulsions were composed of negatively charged droplets at pH 7.0 in our work (Figure 1b). This was because the number of carboxyl groups, which had a negative charge, was greater than the number of positively charged amino groups on proteins. Maximum ZP absolute values of $34.07 \pm 1.27,28.77 \pm 1.17$, $32.93 \pm 1.42$, and $32.40 \pm 1.15 \mathrm{mV}$ were recorded for PPI, RBPI, SPI, and WPI-stabilized nanoemulsions, respectively (Figure 1b). When the protein concentrations were lower or higher, the absolute values of $\mathrm{ZP}$ were decreased. It might be because the aqueous phase ionic strength was different, resulting in electrostatic screening [31]. The ZP values of previous research results were from -2 to $-43 \mathrm{mV}[32,33]$. The relatively high ZP absolute values of PPI-stabilized nanoemulsions demonstrated that its stability was superior to RBPI, SPI, and WPI due to an intense electrostatic repulsion acting between the same charged droplets [32]. 
(a)

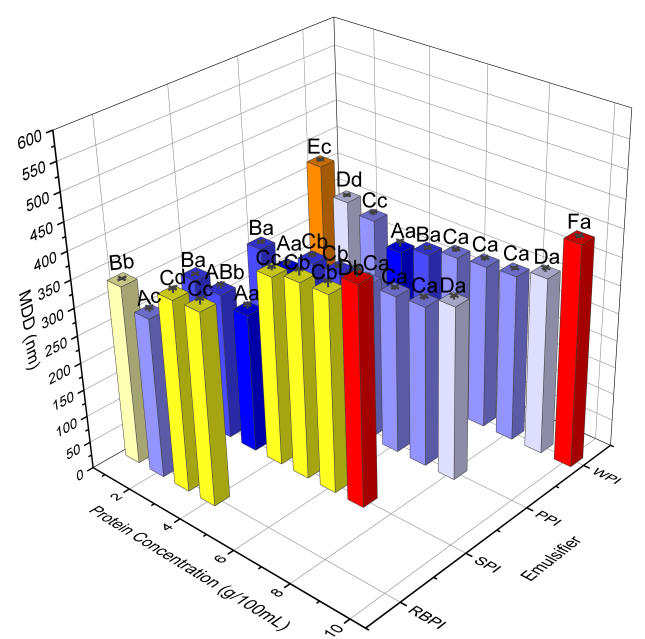

(b)

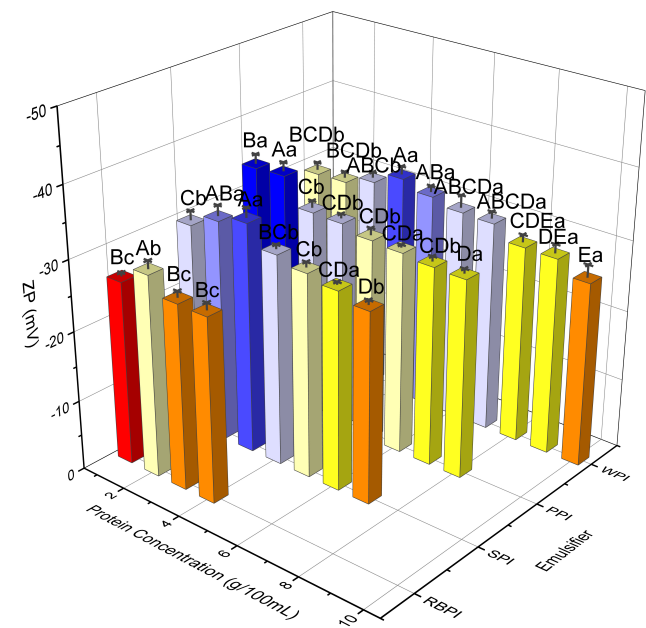

Figure 1. Effects of protein concentrations on MDD (a) and ZP (b) of PPI, RBPI, SPI, and WPI-stabilized nanoemulsions. Samples marked by uppercase letters $(\mathrm{A}-\mathrm{F})$ indicate significant difference $(p<0.05)$ relative to different concentrations of the same protein. Samples marked by lowercase letters (a-d) indicate significant difference $(p<0.05)$ when compared between different proteins of the same concentration. The PPI, RBPI, SPI, and WPI-stabilized nanoemulsions were fabricated under the circumstance of corn oil $(5 \% \mathrm{v} / \mathrm{v})$, ultrasonic power $400 \mathrm{~W}$ and ultrasonic time $15 \mathrm{~min}$.

\subsection{Effects of Oil Phase Fraction on Nanoeumlsions MDD and ZP}

To investigate the influence of oil phase fraction on MDD and ZP, nanoemulsions were produced using different oil phase fraction (Figure 2a). For PPI and WPI-stabilized nanoemulsions, as oil phase fraction increased from $1 \%$ to $3 \%$, the particle size decreased from $249.80 \pm 2.26$ to $227.30 \pm 7.53 \mathrm{~nm}$ and from $275.50 \pm 1.87$ to $245.80 \pm 0.35 \mathrm{~nm}$, respectively. For RBPI and SPI-stabilized nanoemulsions, as oil phase fraction increased from $1 \%$ to $2 \%$ resulted in a decrease in droplet size from $278.70 \pm 1.31$ to $251.53 \pm 3.11 \mathrm{~nm}$ and from $243.57 \pm 0.97$ to $233.40 \pm 0.60 \mathrm{~nm}$, respectively. However, as oil phase fraction further increased to $20 \%$, the MDD of all nanoemulsions began to gradually increase (Figure 2a). Guo and Mu (2011) got similar results in the manufacture of corn oil nanoemulsions using sweet potato protein for emulsifier [34]. The initial reduction in MDD of nanoemulsions could be due to the reduced proportions of unabsorbed protein as the oil phase fraction increased, and thus a decrease in protein molecules aggregation. The subsequent higher oil phase fraction resulted in higher MDD. The phenomenon might be caused by the deficient mass of protein molecules available to overlay the oil droplets, which led to the enhancement of oil droplet coalescence [35].

Figure $2 \mathrm{~b}$ depicts the effect of oil phase fraction on nanoemulsions $\mathrm{ZP}$. The negative $\mathrm{ZP}$ was ranged from -35.23 to $-25.10 \mathrm{mV}$ when oil phase fraction increased from $1 \%$ to $20 \%$. In case of oil phase fraction over 3\% (for PPI and WPI) or 2\% (for RBPI and SPI), ZP absolute value decreased with an increased oil phase fraction. The trend indicated that the electrostatic repulsion between droplets of nanoemulsions was increasingly less able to resist particle coalescence and flocculation. With a further increase in oil phase fraction, the absolute value of ZP decreased and the mean droplet diameter increased more significantly $(p<0.05)$ (Figure 2a). Therefore, the stability of protein-stabilized nanoemulsions decreased. 
(a)

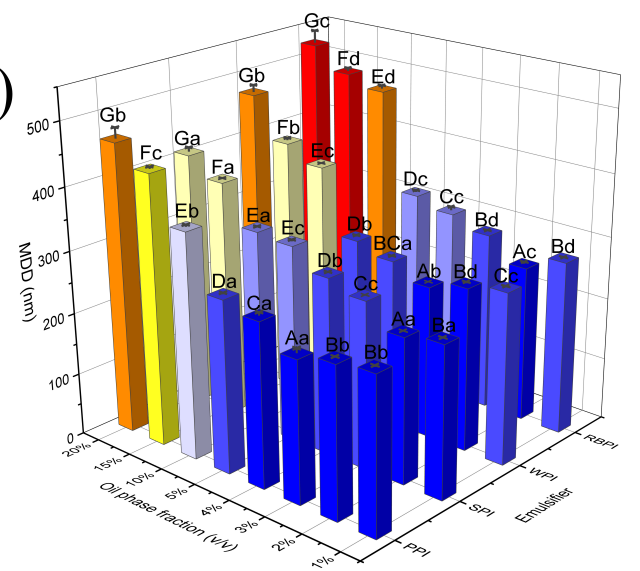

(b)

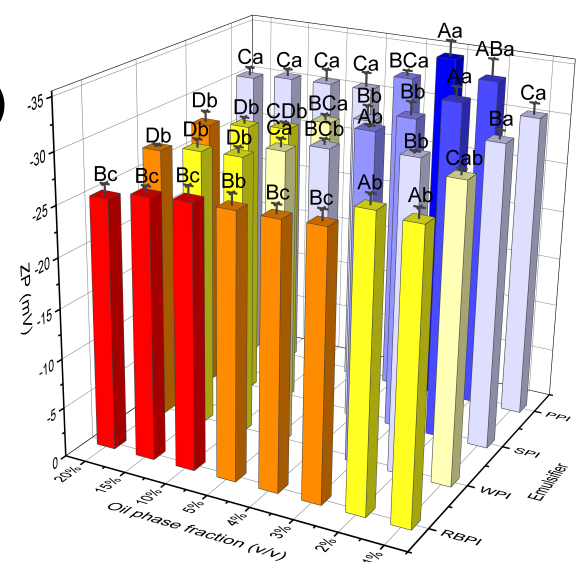

Figure 2. Effects of oil phase fraction on mean droplet diameter (MDD) (a) and zeta potential (ZP) (b) of peanut protein isolate (PPI), rice bran protein isolate (RBPI), soybean protein isolate (SPI), and whey protein isolate (WPI)-stabilized nanoemulsions. Samples marked by uppercase letters (A-G) indicate significant difference $(p<0.05)$ relative to different oil phase fractions. Samples marked by lowercase letters $(\mathrm{a}-\mathrm{d})$ indicate significant difference $(p<0.05)$ when compared between different proteins of the same oil phase fraction. The PPI, RBPI, SPI, and WPI-stabilized nanoemulsions were fabricated under the circumstance of the different protein concentrations of PPI $(2 \% w / v)$, RBPI $(2 \% w / v)$, SPI $(3 \% w / v)$, and WPI $(4 \% w / v)$, ultrasonic power $400 \mathrm{~W}$ and ultrasonic time $15 \mathrm{~min}$.

\subsection{Effects of Ultrasonic Power and Time on Nanoemulsions MDD and ZP}

As described above, the stable nanoemulsions preparation was concerned with the category and content of emulsifier, as well as oil phase fraction applied to droplets. But beyond that, in order to attain a high dispersion of oil droplets in the continuous phase, the high energy input is necessary to destroy the oil-water interface [32]. The determination of optimal ultrasonic power and time is very important for an industrial production of ultrasonic-mediated nanoemulsions. It can reduce energy wastage and cost of manufacture [36].

Increasing the ultrasonic power from 100 to $500 \mathrm{~W}$ led to a significant decrease in MDD $(p<0.05)$ (Figure 3a) and an increase in ZP absolute value (Figure 3b) for PPI, RBPI, SPI, and WPI-stabilized nanoemulsions. The results were similar to those obtained by Abbas et al. (2014) [32]. This was because as ultrasonic power increased, there was a concomitant increase in the applied sound pressure amplitude, thereby increasing cavitation intensity [37]. Then the energy consumption rate of system increased similarly, and the dispersion of one phase to another could be accelerated effectually [38]. Since the energy input was needed to be setup at a suitable condition to obtain a desired particle size, the ultrasonic power was setup at a maximum of $500 \mathrm{~W}$ for the next experiments.

The ultrasonic time represents the processing time of ultrasonic probe in nanoemulsions preparation. Next, nanoemulsions were prepared by varying ultrasonic time, at settled imposed power of $500 \mathrm{~W}$. Effects of different sonication time (5-25 min) on MDD and ZP are in Figure 4. As the ultrasonic time increased from 5 to $25 \mathrm{~min}$, MDD decreased and ZP absolute value increased for four proteins-stabilized nanoemulsions. Ultrasonic time of $20 \mathrm{~min}$ was discovered to be optimal, because there was no significant decrease in MDD over time $(p>0.05)$. In addition, prolonged sonication should be avoided as it might degrade the active ingredients of the product [32]. Therefore, subsequent experiments were performed at $20 \mathrm{~min}$.

Under the optimum ultrasonic preparation conditions, the minimum particle size of PPI, RBPI, SPI, and WPI-stabilized nanoemulsions was $223.77 \pm 1.79,244.97 \pm 1.66,225.40 \pm 2.18,241.03 \pm 2.50 \mathrm{~nm}$, respectively. And the narrow distributions of the four proteins-stabilized nanoemulsions were revealed by the small PDI values $(<0.3)$ (data not shown). PPI and SPI-stabilized nanoemulsions had smaller MDD than RBPI and WPI-stabilized nanoemulsions. 

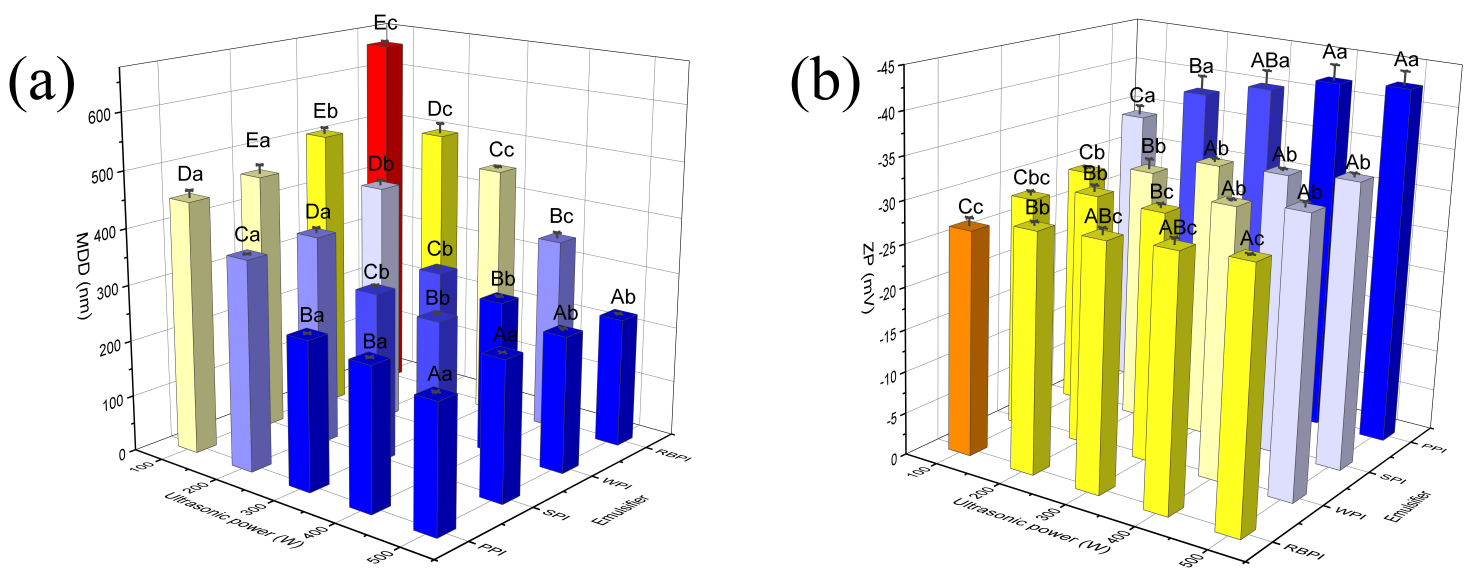

Figure 3. Effects of ultrasonic power on MDD (a) and ZP (b) of PPI, RBPI, SPI, and WPI-stabilized nanoemulsions. Samples marked by uppercase letters (A-E) indicate significant difference $(p<0.05)$ when compared between different ultrasonic power. Samples marked by lowercase letters $(\mathrm{a}-\mathrm{c})$ indicate significant difference $(p<0.05)$ when compared between different proteins of the same ultrasonic power. The PPI, RBPI, SPI, and WPI-stabilized nanoemulsions were fabricated under the circumstance of the different protein concentrations of PPI $(2 \% w / v)$, RBPI $(2 \% w / v)$, SPI $(3 \% w / v)$, and WPI $(4 \% w / v)$, corn oil (3\%, 2\%, 2\%, 3\% v/v, respectively) and ultrasonic time $15 \mathrm{~min}$.

(a)

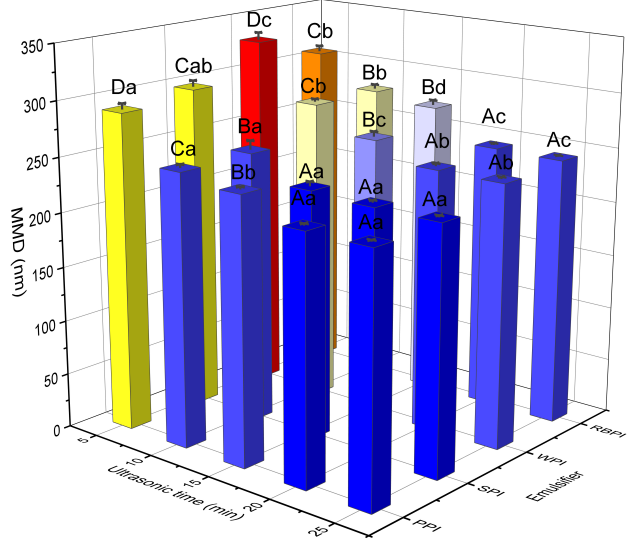

(b)

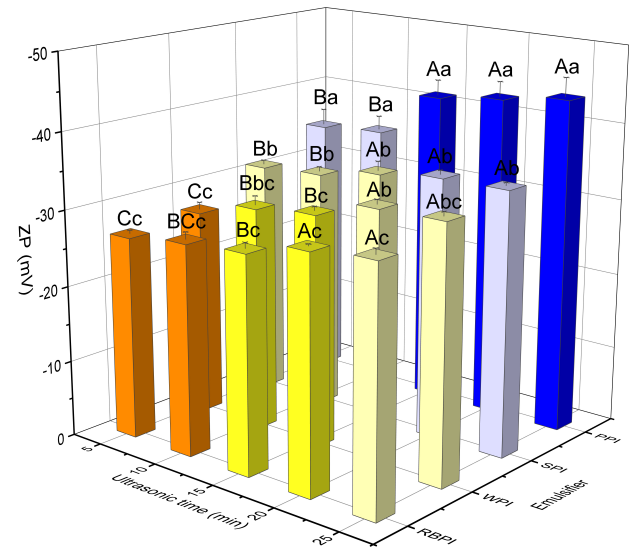

Figure 4. Effects of ultrasonic time on MDD (a) and ZP (b) of PPI, RBPI, SPI, and WPI-stabilized nanoemulsions. Samples marked by uppercase letters (A-D) indicate significant difference $(p<0.05)$ when compared between different ultrasonic time. Samples marked by lowercase letters $(a-d)$ indicate significant difference $(p<0.05)$ when compared between different proteins of the same ultrasonic time. The PPI, RBPI, SPI and WPI-stabilized nanoemulsions were fabricated under the circumstance of the different protein concentrations of PPI $(2 \% w / v)$, RBPI $(2 \% w / v)$, SPI $(3 \% w / v)$ and WPI $(4 \% w / v)$, corn oil $(3 \%, 2 \%, 2 \%, 3 \% v / v$, respectively) and ultrasonic power $500 \mathrm{~W}$.

\subsection{Apparent Viscosity of Nanoemulsions}

The rheology of emulsion-based food systems is important because it influences their processing, functional properties and sensory attributes. The viscosities of four different protein-stabilized nanoemulsions are shown in Figure 5. For PPI, SPI and WPI-stabilized nanoemulsions, the slight shear thinning behavior was found when the shear rates were lower than $1 \mathrm{~s}^{-1}$; beyond this point, the viscosities no longer changed significantly as shear rate changed. For RBPI-stabilized nanoemulsions, the slight shear thinning behavior was found at shear rates below $10 \mathrm{~s}^{-1}$. This behavior was concerned with the aggregation of emulsions droplets, when the shear rate was sufficient to conquer Brownian motion, the nanoemulsions droplets were increasingly ordered within the flow field, offering less flow resistance and thus decreasing viscosity [39]. At high shear rate no significant viscosity changes were 
observed for four different protein-stabilized nanoemulsions, with behavior like that of high-shear Newtonian fluid [40]. However, the RBPI-stabilized nanoemulsions presented marginally higher viscosity and greater shear thinning than PPI, SPI and WPI-stabilized nanoemulsions at low shear rate values. This indicated that the structure of RBPI was destroyed and the protein molecules were aggregated during shearing process, which resulted in the larger size of RBPI-stabilized nanoemulsions than other three protein-stabilized nanoemulsions. And the results were further confirmed by confocal laser scanning micrographs of nanoemulsions (Figure 6).

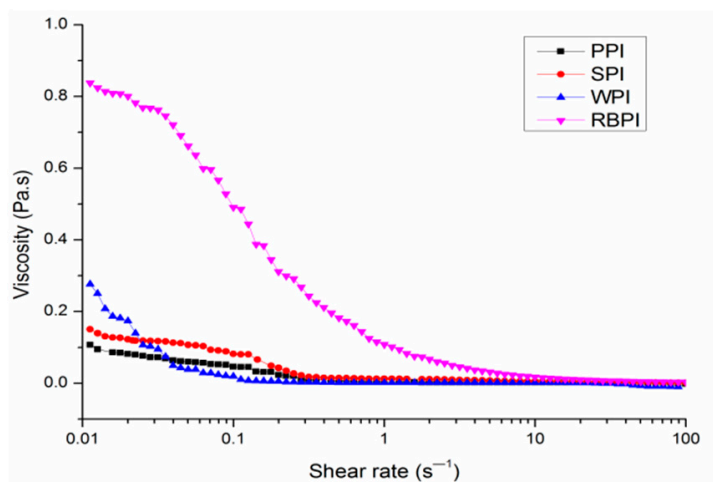

Figure 5. Rheological properties of PPI, SPI, WPI, and RBPI-stabilized nanoemulsions. The PPI, RBPI, SPI, and WPI-stabilized nanoemulsions were fabricated under the circumstance of the different protein concentrations of PPI $(2 \% w / v)$, RBPI $(2 \% w / v)$, SPI $(3 \% w / v)$, and WPI $(4 \% w / v)$, corn oil $(3 \%, 2 \%, 2 \%$, $3 \% v / v$, respectively), ultrasonic power $500 \mathrm{~W}$ and ultrasonic time $20 \mathrm{~min}$.

\subsection{Microstructure of Nanoemulsions}

The microstructure of nanoemulsions was evaluated using confocal laser scanning microscopy (Figure 6). All nanoemulsions stabilized by four different proteins presented quite exquisite and uniform distributed droplets. And no intense interconnected oil droplets and protein networks were observed, which suggested that these proteins were effective emulsifier for stabilizing nanoemulsions. Luo et al. (2017) also viewed fairly exquisite droplets of dual-channel microfluidizer-mediated nanoemulsions, which were stabilized by WPI as emulsifier [41]. However, RBPI-stabilized nanoemulsions showed marginally larger oil droplets in comparison with PPI, SPI and WPI-stabilized nanoemulsions. The little increase of droplet size in RBPI-stabilized nanoemulsions might be the droplets coalescence phenomena, because RBPI-stabilized nanoemulsions had larger droplet size and lower ZP value (Figure 4). The higher viscosity of RBPI-stabilized nanoemulsions made droplets more likely to aggregate (Figure 5).
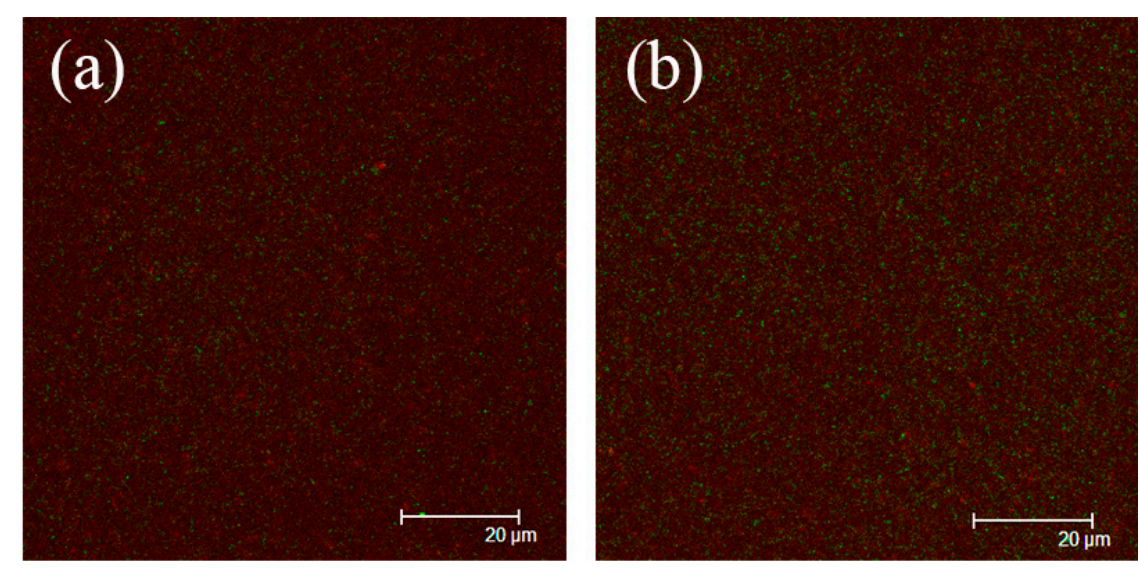

Figure 6. Cont. 

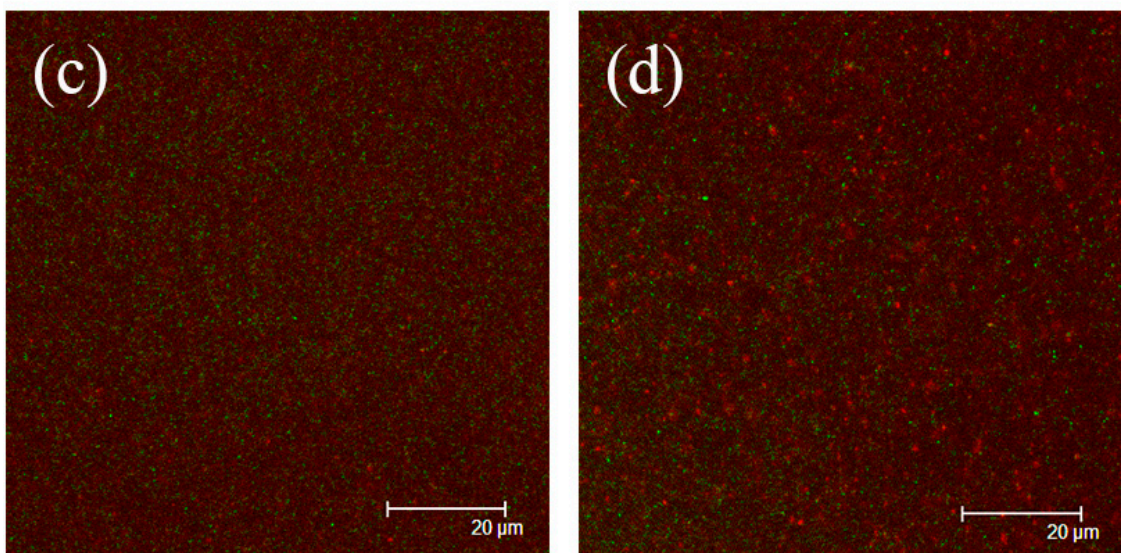

Figure 6. Confocal laser scanning micrographs of PPI (a), SPI (b), WPI (c), and RBPI (d)-stabilized corn oil nanoemulsions. The PPI, RBPI, SPI, and WPI-stabilized nanoemulsions were fabricated under the circumstance of the different protein concentrations of PPI $(2 \% w / v)$, RBPI $(2 \% w / v), \operatorname{SPI}(3 \% w / v)$, and WPI $(4 \% w / v)$, corn oil $(3 \%, 2 \%, 2 \%, 3 \% v / v$, respectively), ultrasonic power $500 \mathrm{~W}$ and ultrasonic time $20 \mathrm{~min}$.

\subsection{Storage Stability of Nanoemulsions}

The effects of storage time on PPI, RBPI, SPI, and WPI-stabilized nanoemulsions physical and oxidative stability were determined (Figure 7). The nanoemulsions were stored under the condition of $4{ }^{\circ} \mathrm{C}$ for 4 weeks.
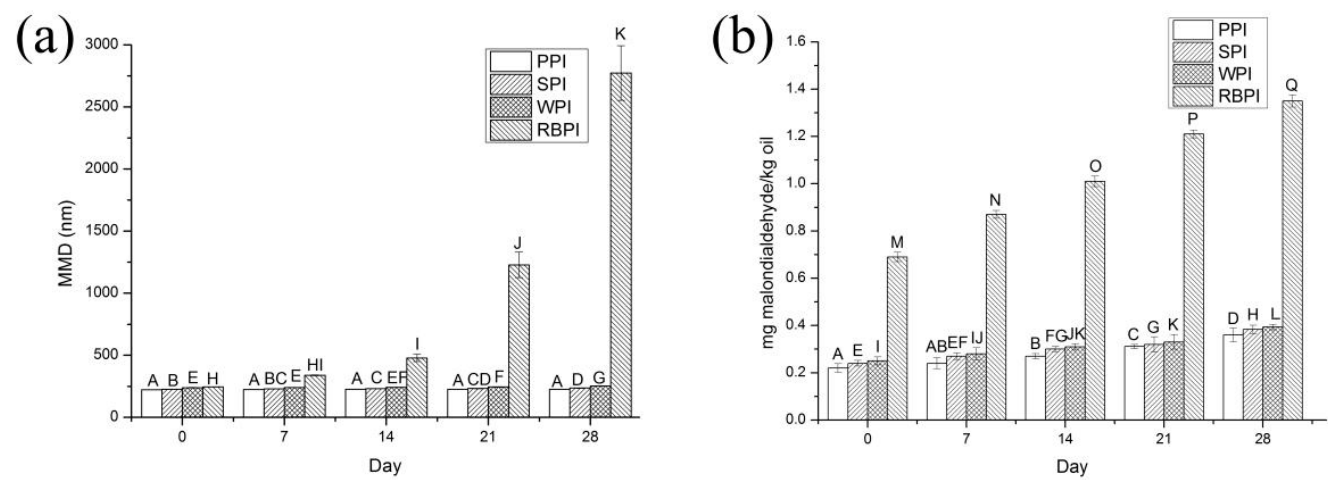

Figure 7. Influence of storage time on MDD (a) and thiobarbituric acid-reactive substances (TBARS) values (b) of PPI, SPI, WPI, and RBPI-stabilized nanoemulsions. Samples designated with different uppercase letters $(A),(B-D),(E-G)$, and $(H-K)$ indicate significant difference $(p<0.05)$ when compared with different storage time on MDD of PPI, SPI, WPI, and RBPI -stabilized nanoemulsions, respectively. Samples designated with different upper case letters (A-D), (E-H), (I-L) and (M-Q) indicate significant difference $(p<0.05)$ when compared between different storage time on TBARS values of PPI, SPI, WPI, and RBPI-stabilized nanoemulsions, respectively. The PPI, RBPI, SPI, and WPI-stabilized nanoemulsions were fabricated under the circumstance of the different protein concentrations of PPI $(2 \% w / v)$, RBPI $(2 \% w / v)$, SPI $(3 \% w / v)$, and WPI $(4 \% w / v)$, corn oil $(3 \%, 2 \%, 2 \%, 3 \% v / v$, respectively), ultrasonic power $500 \mathrm{~W}$ and ultrasonic time $20 \mathrm{~min}$.

\subsubsection{Physical Stability}

Physical stability of nanoemulsions is an essential factor to decide their suitability for application in food industries. The PPI, SPI, and WPI-stabilized nanoemulsions presented favorable resistance to phase separation during storage. Especially, PPI formed the most physically stable nanoemulsions, with no significant variation in particle size over time $(p>0.05)$ (Figure 7a). The MDD changed from $223.77 \pm 1.79$ to $226.63 \pm 2.06 \mathrm{~nm}$ in PPI-stabilized nanoemulsions. This might be ascribed to the 
fact that the emulsion droplets were fairly stable to gravity separation, forming a stout interfacial film to resist cracking [42,43]. However, a great MDD variation with time could be observed for RBPI-stabilized nanoemulsions. The MDD of RBPI-stabilized nanoemulsions was greater than $1000 \mathrm{~nm}$ after 3 weeks. And the PDI values of RBPI-stabilized nanoemulsions were greater than 0.3 after 3 weeks (data not shown). The results indicated that some formation of droplet aggregation had occurred, such as flocculation or coalescence, resulting in poor physical stability during storage. From the above experiments we could arrive at the conclusion that PPI, SPI, and WPI-stabilized nanoemulsions revealed appropriate stability at $4{ }^{\circ} \mathrm{C}$ for 4 weeks.

\subsubsection{Oxidative Stability}

The oxidative stability of PPI, RBPI, SPI, and WPI-stabilized nanoemulsions was analyzed by quantifying malondialdehyde (Figure $7 \mathrm{~b}$ ). At the initial phase of storage, all nanoemulsions had an increase in TBARS values, suggesting that lipid oxidation had occurred. And the increase in TBARS values of the RBPI-stabilized nanoemulsions during storage was very significant $(p<0.05)$, which might be concerned with the occurrence of droplet coalescence. The coalescence might result in a closer lipid phase, thus promoting the movement of the pro-oxidants in the oil phase [44]. The TBARS values of the nanoemulsions stabilized by PPI had been the lowest of the four proteins during storage. This could be because that the far higher negative charge of PPI-stabilized nanoemulsions (Figure $4 \mathrm{~b}$ ) was more intense in combination with transition metal irons, resulting in that the nanoemulsion was more stable [45]. The maximum malondialdehyde content of the four proteins-stabilized nanoemulsions during storage was $1.35 \pm 0.03 \mathrm{mg} / \mathrm{kg}$ oil. However, the quantities of oxidation products produced during 4 weeks of storage were below the maximum endurable standard (1-2 mg of malondialdehyde $/ \mathrm{kg}$ oil), indicating no effect on the quality of the products [43].

\subsection{Characteristics of Proteins}

\subsubsection{Secondary Structure}

When the protein spread out at the two-phase interface, its specific distribution in the oil-water phase is related to its secondary structure. The ratios of $\alpha$-helix, $\beta$-sheet, $\beta$-turn, and random coil for these four proteins were listed in Table 1. For PPI, the contents of ordered structure $(\alpha$-helix $+\beta$-sheet) were relatively low, and the contents of unordered structure ( $\beta$-turn + random coil) were relatively high, while the unordered structure contents of RBPI were relatively smaller. It had shown that an increasingly disordered structure can improve adsorption at the oil-water interface, enhancing emulsifying properties [46]. It could also be seen that PPI-stabilized nanoemulsions had the smallest particle size (Figure 4a). And the PPI-stabilized nanoemulsions were pretty stable to droplet aggregation during storage, while the stability of RBPI-stabilized nanoemulsions was relatively poor (Figure 7a).

Table 1. Secondary structure contents of PPI, RBPI, SPI, and WPI protein dispersions.

\begin{tabular}{ccccc}
\hline Sample & $\boldsymbol{\alpha}$-Helix (\%) & $\beta$-Sheet (\%) & $\beta$-Turn (\%) & Random Coil (\%) $^{\text {(\%) }}$ \\
\hline PPI & $12.01 \pm 0.03^{\mathrm{a}}$ & $30.17 \pm 0.03^{\mathrm{a}}$ & $41.76 \pm 0.03^{\mathrm{d}}$ & $16.06 \pm 0.03^{\mathrm{d}}$ \\
RBPI & $16.90 \pm 0.01^{\mathrm{d}}$ & $34.63 \pm 0.03^{\mathrm{c}}$ & $34.64 \pm 0.02^{\mathrm{b}}$ & $13.83 \pm 0.01^{\mathrm{a}}$ \\
SPI & $12.84 \pm 0.02^{\mathrm{b}}$ & $31.44 \pm 0.03^{\mathrm{b}}$ & $40.99 \pm 0.04^{\mathrm{c}}$ & $14.72 \pm 0.02^{\mathrm{c}}$ \\
WPI & $15.68 \pm 0.02^{\mathrm{c}}$ & $35.65 \pm 0.02^{\mathrm{d}}$ & $34.11 \pm 0.04^{\mathrm{a}}$ & $14.56 \pm 0.03^{\mathrm{b}}$ \\
\hline \multicolumn{4}{r}{}
\end{tabular}

\subsubsection{Interfacial Characteristics}

The formation and stability of nanoemulsions are related to the nature of the emulsifiers, which is dependent upon the characteristics of the interface layer surrounding the oil droplets. Thus, interfacial tensions were measured at different protein concentrations (Figure 8). The lower the interfacial tension 
of the protein indicates the smaller the particle size of the nanoemulsion formation, because less destructive forces are required to break the droplets during preparation [47]. The initial IT between corn oil and distilled water was $21.3 \pm 0.2 \mathrm{mN} / \mathrm{m}$. The IT of four proteins appeared to decline gradually as concentrations increased, indicating that the protein molecules adsorbed to the oil/water interface and shielded the unfavorable molecular interactions between oil and water [48]. Compared with RBPI, PPI was more effective at lowering IT with small concentration. This might be because the PPI-stabilized nanoemulsions had higher ZP values (Figure $4 b$ ), resulting in greater repulsive forces between protein molecules. The repulsive forces caused the protein molecules to unfold and better adsorb at the oil/water interface [23]. This might explain that PPI based nanoemulsions had higher stability among four nanoemulsions (Figure 7).

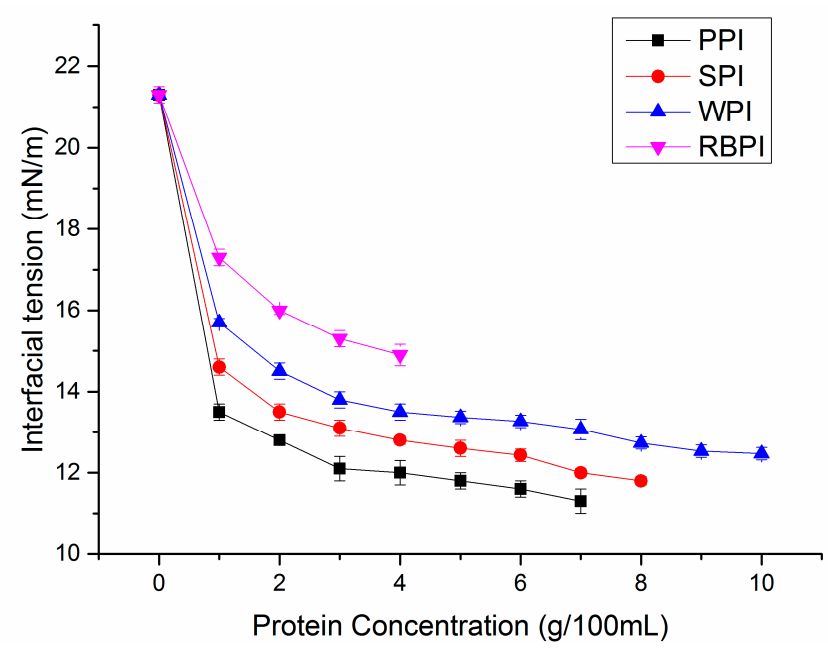

Figure 8. Influence of different concentrations of PPI, SPI, WPI, and RBPI protein dispersions on interfacial tension against corn oil.

\subsection{Correlation Analysis}

In this study, the data of nanoemulsions prepared under optimal conditions of four proteins were selected as typical for analyzing the correlation between protein secondary structure, MDD, and ZP. As shown in Table 2, the correlation analysis showed that $\alpha$-helix $(p<0.01)$ and $\beta$-turn $(p<0.05)$ of protein were significantly correlated with the MDD of nanoemulsions, the random coil $(p<0.05)$ was significantly related to the ZP of nanoemulsions. It was obvious that differences in protein structure could affect characteristics of nanoemulsions. The results further confirmed that the disordered structure of protein was conducive to the formation and stabilization of the nanoemulsions.

Table 2. Correlation analysis between the structure of protein and properties of protein-stabilized nanoemulsions.

\begin{tabular}{ccccccc}
\hline & $\alpha$-Helix & $\beta$-Sheet & $\beta$-Turn & Random & MDD & ZP \\
\hline$\alpha$-Helix & 1 & & & & & \\
$\beta$-Sheet & 0.928 & 1 & & & & \\
$\beta$-Turn & $-0.961^{*}$ & $-0.986^{*}$ & 1 & & & \\
Random & -0.872 & -0.784 & 0.767 & 1 & 1 & \\
MDD & $0.994^{* *}$ & 0.942 & $-0.979 *$ & -0.817 & 1 \\
ZP & 0.824 & 0.808 & -0.761 & $-0.980^{*}$ & 0.773 & 1 \\
\hline
\end{tabular}

Value indicated by an asterisk is significant at the 0.05 level $(p<0.05)$. Value represented by two asterisks is significant at the 0.01 level $(p<0.01)$. 


\section{Conclusions}

PPI and RBPI could produce nanoemulsions with fairly uniform small droplets ( $<300 \mathrm{~nm})$ as efficiently as WPI and SPI. The nanoemulsions formed by PPI had a smaller MDD and a higher ZP as compared to SPI, RBPI and WPI. Furthermore, PPI, SPI and WPI-stabilized nanoemulsions exhibited substantial stability during 4 weeks storage at $4{ }^{\circ} \mathrm{C}$. RBPI-stabilized nanoemulsions were less stable, and the mean droplet diameter had exceeded $1000 \mathrm{~nm}$ during the third week of storage. The results indicated that PPI was an excellent emulsifier for preparing nanoemulsions. The more disordered structure and lower IT of protein was favorable to form stable nanoemulsions. The correlation analysis revealed that the MDD of nanoemulsions was affected by $\alpha$-helix $(p<0.01)$ and $\beta$-turn $(p<0.05)$ of protein, and the ZP of nanoemulsions was affected by random coil of protein $(p<0.05)$. The research provided novel insights regarding the relationship between protein structure, the formation and stabilization of protein-stabilized nanoemulsions.

Author Contributions: Y.L. performed experiments and drafted the manuscript. H.J. designed experiments and drafted the manuscript, too. Notably, Y.L. and H.J. contributed equally to this work and should be considered co-first authors. X.S., J.S. and C.L. (Chang Liu) analyzed the experimental data and form. C.L. (Chunhong Liu) revised the manuscript. J.X. was the project manager who supplied the funding of this work and revised the manuscript, too. All authors reviewed the manuscript.

Funding: This work was supported by the National Natural Science Foundation of China [No. 31301600], the Natural Science Foundation of Heilongjiang Province [No. LC2017010], Postdoctoral project in Heilongjiang Province [LBH-Q16012] and Academic Backbone Project of Northeast Agricultural University [17XG02].

Conflicts of Interest: The authors declare no conflict of interest.

\section{References}

1. Guerra-Rosas, M.I.; Morales-Castro, J.; Ochoa-Martínez, L.A.; Salvia-Trujillo, L.; Martín-Belloso, O. Long-term stability of food-grade nanoemulsions from high methoxyl pectin containing essential oils. Food Hydrocoll. 2016, 52, 438-446. [CrossRef]

2. Odriozola-Serrano, I.; Oms-Oliu, G.; Martín-Belloso, O. Nanoemulsion-based delivery systems to improve functionality of lipophilic components. Front. Nutr. 2014, 1, 1-4. [CrossRef] [PubMed]

3. Mcclements, D.J. Nanoemulsion-based oral delivery systems for lipophilic bioactive components: Nutraceuticals and pharmaceuticals. Ther. Deliv. 2013, 4, 841-857. [CrossRef] [PubMed]

4. Silva, H.D.; Cerqueira, M.Â.; Vicente, A.A. Nanoemulsions for food applications: Development and characterization. Food Bioprocess Technol. 2012, 5, 854-867. [CrossRef]

5. Ezhilarasi, P.N.; Karthik, P.; Chhanwal, N.; Anandharamakrishnan, C. Nanoencapsulation techniques for food bioactive components: A review. Food Bioprocess Technol. 2013, 6, 628-647. [CrossRef]

6. Mcclements, D.J. Edible nanoemulsions: Fabrication, properties, and functional performance. Soft Matter 2011, 7, 2297-2316. [CrossRef]

7. Peshkovsky, A.S.; Peshkovsky, S.L.; Bystryak, S. Scalable high-power ultrasonic technology for the production of translucent nanoemulsions. Chem. Eng. Process. Process Intensif. 2013, 69, 77-82. [CrossRef]

8. Kaltsa, O.; Michon, C.; Yanniotis, S.; Mandala, I. Ultrasonic energy input influence on the production of sub-micron o/w emulsions containing whey protein and common stabilizers. Ultrason. Sonochem. 2013, 20, 881-891. [CrossRef]

9. Gordon, L.; Pilosof, A.M.R. Application of high-intensity ultrasounds to control the size of whey proteins particles. Food Biophys. 2010, 5, 203-210. [CrossRef]

10. Kumar, R.; Kaur, K.; Uppal, S.; Mehta, S.K. Ultrasound processed nanoemulsion: A comparative approach between resveratrol and resveratrol cyclodextrin inclusion complex to study its binding interactions, antioxidant activity and UV light stability. Ultrason. Sonochem. 2017, 37, 478-489. [CrossRef]

11. Sivakumar, M.; Tang, S.Y.; Tan, K.W. Cavitation technology-A greener processing technique for the generation of pharmaceutical nanoemulsions. Ultrason. Sonochem. 2014, 21, 2069-2083. [CrossRef] [PubMed]

12. Alzorqi, I.; Ketabchi, M.R.; Sudheer, S.; Manickam, S. Optimization of ultrasound induced emulsification on the formulation of palm-olein based nanoemulsions for the incorporation of antioxidant $\beta$-d-glucan polysaccharides. Ultrason. Sonochem. 2016, 31, 71-84. [CrossRef] [PubMed] 
13. Tang, S.Y.; Manickam, S.; Wei, T.K.; Nashiru, B. Formulation development and optimization of a novel Cremophore EL-based nanoemulsion using ultrasound cavitation. Ultrason. Sonochem. 2012, 19, 330-345. [CrossRef] [PubMed]

14. Tang, S.Y.; Sivakumar, M.; Nashiru, B. Impact of osmotic pressure and gelling in the generation of highly stable single core water-in-oil-in-water $(\mathrm{W} / \mathrm{O} / \mathrm{W})$ nano multiple emulsions of aspirin assisted by two-stage ultrasonic cavitational emulsification. Colloid Surf. B 2013, 102, 653-658. [CrossRef] [PubMed]

15. Tang, S.Y.; Sivakumar, M.; Ng, A.M.; Shridharan, P. Anti-inflammatory and analgesic activity of novel oral aspirin-loaded nanoemulsion and nano multiple emulsion formulations generated using ultrasound cavitation. Int. J. Pharm. 2012, 430, 299-306. [CrossRef] [PubMed]

16. Wu, J.; Shi, M.; Li, W.; Zhao, L.; Wang, Z.; Yan, X.; Norde, W.; Li, Y. Pickering emulsions stabilized by whey protein nanoparticles prepared by thermal cross-linking. Colloid Surf. B 2015, 127, 96-104. [CrossRef] [PubMed]

17. Dickinson, E. Structuring of colloidal particles at interfaces and the relationship to food emulsion and foam stability. J. Colloid Interface Sci. 2015, 449, 38-45. [CrossRef]

18. Relkin, P.; Shukat, R.; Bourgaux, C.; Meneau, F. Nanostructures and polymorphisms in protein stabilised lipid nanoparticles, as food bioactive carriers: Contribution of particle size and adsorbed materials. Procedia Food Sci. 2011, 1, 246-250. [CrossRef]

19. Donsi, F.; Senatore, B.; Huang, Q.; Ferrari, G. Development of novel pea protein-based nanoemulsions for delivery of nutraceuticals. J. Agric. Food Chem. 2010, 58, 10653-10660. [CrossRef]

20. Karaca, A.C.; Low, N.; Nickerson, M. Emulsifying properties of chickpea, faba bean, lentil and pea proteins produced by isoelectric precipitation and salt extraction. Food Res. Int. 2011, 44, 2742-2750. [CrossRef]

21. Beliciu, C.M.; Moraru, C.I. The effect of protein concentration and heat treatment temperature on micellar casein-soy protein mixtures. Food Hydrocoll. 2011, 25, 1448-1460. [CrossRef]

22. Amine, C.; Dreher, J.; Helgason, T.; Tadros, T. Investigation of emulsifying properties and emulsion stability of plant and milk proteins using interfacial tension and interfacial elasticity. Food Hydrocoll. 2014, 39, 180-186. [CrossRef]

23. Han, S.W.; Chee, K.M.; Cho, S.J. Nutritional quality of rice bran protein in comparison to animal and vegetable protein. Food Chem. 2015, 172, 766-769. [CrossRef] [PubMed]

24. Zhang, S.B.; Lu, Q.Y. Characterizing the structural and surface properties of proteins isolated before and after enzymatic demulsification of the aqueous extract emulsion of peanut seeds. Food Hydrocoll. 2015, 47, 51-60. [CrossRef]

25. Zhang, L.; Pan, Z.; Shen, K.; Cai, X.; Zheng, B.; Miao, S. Influence of ultrasound-assisted alkali treatment on the structural properties and functionalities of rice protein. J. Cereal Sci. 2018, 79, 204-209. [CrossRef]

26. Nejadmansouri, M.; Hosseini, S.M.H.; Niakosari, M.; Yousefi, G.H.; Golmakani, M.T. Physicochemical properties and storage stability of ultrasound-mediated wpi-stabilized fish oil nanoemulsions. Food Hydrocoll. 2016, 61, 801-811. [CrossRef]

27. Wang, X.B.; Chi, Y.J. Microwave-assisted phosphorylation of soybean protein isolates and their physicochemical properties. Czech J. Food Sci. 2012, 30, 99-107. [CrossRef]

28. Ziani, K.; Barish, J.A.; McClementsm, D.J.; Goddard, J.M. Manipulating interactions between functional colloidal particles and polyethylene surfaces using interfacial engineering. J. Colloid Interface Sci. 2011, 360, 31-38. [CrossRef]

29. Tcholakova, S.; Denkov, N.D.; Danner, T. Role of surfactant type and concentration for the mean drop size during emulsification in turbulent flow. Langmuir 2004, 20, 7444-7458. [CrossRef]

30. Primozic, M.; Duchek, A.; Nickerson, M.; Ghosh, S. Effect of lentil proteins isolate concentration on the formation, stability and rheological behavior of oil-in-water nanoemulsions. Food Chem. 2017, 237, 65-74. [CrossRef]

31. Chen, E.; Cao, L.; Mcclements, D.J.; Liu, S.; Li, B.; Li, Y. Enhancement of physicochemical properties of whey protein-stabilized nanoemulsions by interfacial cross-linking using cinnamaldehyde. Food Hydrocoll. 2017, 77, 976-985. [CrossRef]

32. Abbas, S.; Bashari, M.; Akhtar, W.; Li, W.W.; Zhang, X. Process optimization of ultrasound-assisted curcumin nanoemulsions stabilized by OSA-modified starch. Ultrason. Sonochem. 2014, 21, 1265-1274. [CrossRef] [PubMed] 
33. Charoen, R.; Jangchud, A.; Jangchud, K.; Harnsilawat, T.; Decker, E.A.; McClements, D.J. Influence of interfacial composition on oxidative stability of oil-in-water emulsions stabilized by biopolymer emulsifiers. Food Chem. 2012, 131, 1340-1346. [CrossRef]

34. Guo, Q.; Mu, T.H. Emulsifying properties of sweet potato protein: Effect of protein concentration and oil volume fraction. Food Hydrocoll. 2011, 25, 98-106. [CrossRef]

35. Hu, K.; Huang, X.; Gao, Y.; Huang, X.; Xiao, H.; McClements, D.J. Core-shell biopolymer nanoparticle delivery systems: Synthesis and characterization of curcumin fortified zein-pectin nanoparticles. Food Chem. 2015, 182, 275-281. [CrossRef] [PubMed]

36. Prasad, K.; Pinjari, D.V.; Pandit, A.B.; Mhaske, S.T. Synthesis of titanium dioxide by ultrasound assisted sol-gel technique: Effect of amplitude (power density) variation. Ultrason. Sonochem. 2010, 17, 697-703. [CrossRef] [PubMed]

37. Wang, Y.; Wang, Z.; Handa, C.L.; Xu, J. Effects of ultrasound pre-treatment on the structure of $\beta$-conglycinin and glycinin and the antioxidant activity of their hydrolysates. Food Chem. 2017, 218, 165-172. [CrossRef] [PubMed]

38. Jadhav, A.J.; Holkar, C.R.; Karekar, S.E.; Pinjari, D.V.; Pandit, A.B. Ultrasound assisted manufacturing of paraffin wax nanoemulsions: Process optimization. Ultrason. Sonochem. 2015, 23, 201-207. [CrossRef]

39. Khalloufi, S.; Alexander, M.; Goff, H.D.; Corredig, M. Physicochemical properties of whey protein isolate stabilized oil-in-water emulsions when mixed with flaxseed gum at neutral pH. Food Res. Int. 2008, 41, 964-972. [CrossRef]

40. Rodea-González, D.A.; Cruz-Olivares, J.; Román-Guerrero, A.; Rodríguez-Huezo, M.E.; Vernon-Carter, E.J.; Pérez-Alonso, C. Spray-dried encapsulation of chia essential oil (Salvia hispanica L.) in whey protein concentrate-polysaccharide matrices. J. Food Eng. 2012, 111, 102-109. [CrossRef]

41. Luo, X.; Zhou, Y.; Bai, L.; Liu, F.; Deng, Y.; Mcclements, D.J. Fabrication of $\beta$-carotene nanoemulsion-based delivery systems using dual-channel microfluidization: Physical and chemical stability. J. Colloid Interface Sci. 2017, 490, 328-335. [CrossRef] [PubMed]

42. Kentish, S.; Wooster, T.J.; Ashokkumar, M.; Balachandran, S.; Mawson, R.; Simons, L. The use of ultrasonics for nanoemulsion preparation. Innov. Food Sci. Emerg. 2008, 9, 170-175. [CrossRef]

43. Adjonu, R.; Doran, G.; Torley, P.; Agboola, S. Formation of whey protein isolate hydrolysate stabilised nanoemulsion. Food Hydrocoll. 2014, 41, 169-177. [CrossRef]

44. Chityala, P.K.; Khouryieh, H.; Williams, K.; Conte, E. Effect of xanthan/enzyme-modified guar gum mixtures on the stability of whey protein isolate stabilized fish oil-in-water emulsions. Food Chem. 2016, 212, 332-340. [CrossRef] [PubMed]

45. Qiu, C.; Zhao, M.; Mcclements, D.J. Improving the stability of wheat protein-stabilized emulsions: Effect of pectin and xanthan gum addition. Food Hydrocoll. 2015, 43, 377-387. [CrossRef]

46. Mu, L.; Zhao, M.; Yang, B.; Zhao, H.; Cui, C.; Zhao, Q. Effect of ultrasonic treatment on the graft reaction between soy protein isolate and gum acacia and on the physicochemical properties of conjugates. J. Agric. Food Chem. 2010, 58, 4494-4499. [CrossRef]

47. Xiang, L.; Zhou, Y.; Long, B.; Liu, F.; Zhang, R.; Zhang, Z.; Zheng, B.; Deng, Y.; McClements, D.J. Production of highly concentrated oil-in-water emulsions using dual-channel microfluidization: Use of individual and mixed natural emulsifiers (saponin and lecithin). Food Res. Int. 2017, 96, 103-112.

48. Gu, L.; Su, Y.; Zhang, M.; Chang, C.; Li, J.; McClements, D.J.; Yang, Y. Protection of $\beta$-carotene from chemical degradation in emulsion-based delivery systems using antioxidant interfacial complexes: Catechin-egg white protein conjugates. Food Res. Int. 2017, 96, 84-93. [CrossRef]

(C) 2018 by the authors. Licensee MDPI, Basel, Switzerland. This article is an open access article distributed under the terms and conditions of the Creative Commons Attribution (CC BY) license (http://creativecommons.org/licenses/by/4.0/). 